\title{
Effect of UPPP on vascular reactivity of patients with OSAS
}

\author{
Vural Fidan* and Leman Veziroglu Birdane \\ Department of Otorhinolaryngology, Yunus Emre Goverment Hospital, 26100 Eskisehir, Turkeyt
}

\begin{abstract}
Objective: The effect of uvulopalatopharyngoplasty (UPPP) on the endothelial function have not been evaluated in patients with obstructive sleep apnea syndrome (OSAS) in the literature. We investigated the vasoreactivity in patients with OSAS before and after UPPP via intravenous injection of the vitamin C comparing with healty control group.

Methods: This prospective observational study included 39 patients who were admitted with the diagnosis of OSAS and 27 healty controls. The patients were operated which is named UPPP. The anthropometric measures, routine blood tests, polysomnography (PSG) and flow mediated dilatation (FMD) were measured in all subjects. All measurements were repeated 8 weeks after UPPP in study group. Chi-square test and ANOVA tests were used for statistical analysis where appropriate.

Results: No statistically significant difference was observed between the two groups in the anthropometric features, blood pressure, PSG results (except apneahypopnea, oxygen desaturation index) and blood parameters. The preoperative baseline FMD was significantly lower in the study group when compared with the control group ( $\mathrm{p}<0.001)$. After intravenous vitamin $\mathrm{C}$, vasoreactivity unchanged in the control group ( $\mathrm{p}=0.912)$. In the study group, vitamin $\mathrm{C}$ led to a statistically significant increase in preoperative FMD when compared with the preoperative baseline FMD ( $\mathrm{p}<0.001$ ). The preoperative baseline FMD was increased after UPPP $(\mathrm{p}<0.001)$. After UPPP in study group, vitamin $\mathrm{C}$ injection did not change the vasoreactivity $(\mathrm{p}=0.610)$.
\end{abstract}

Conclusion: It was concluded that UPPP could increase vascular reactivity in patients with OSAS.

\section{Introduction}

Obstructive sleep apnea syndrome (OSAS) is a common pathologic condition qualified by apnea / hypopnea episodes during sleep. OSAS is associated with a significant increase in the risk for developing cardiovascular diseases [1-6]. Several mechanisms have been announced for the close relation between OSAS and cardiovascular diseases including circulating oxidative products, systemic inflammation, increase in sympathetic activity and blood pressure [5,7]. Abnormal oxygenation and pressures result in the disturbance of the vascular micromilieu, sympathetic nevre activity, disturbed endothelial function and haemodynamic instabilty [5,7-9]. Vitamins such as vitamin $\mathrm{C}$ or vitamin $\mathrm{E}$ have antioxidant effect [10]. And these vitamins can improve the endothelial function in patients with OSAS [11,12]. OSAS can be healed via continuous positive airway pressure (CPAP) treatment, oral appliances or surgical approach (such as uvulopalatopharyngoplasty (UPPP)) [13,14].

To our knowledge, there is no published study addressing the effect of UPPP surgery on the endothelial function in patients with OSAS. Therefore, we studied the vasoreactivity in patients with OSAS before and after UPPP via intravenous injection of the vitamin C comparing with healty control group.

\section{Materials and methods}

\section{Study population}

Fourty nonsmoking, otherwise healthy patients who were refered to Eskisehir Yunus Emre Goverment Hospital Sleep Laboratory, between June 2011 and July 2012 were included in this study. One of them was excluded from the study; because he had a significant change in his body weight. So study completed with 39 patients (age range 31-50years (mean \pm SD age, $41.4 \pm 7.9)$ ). Twenty-seven age and gender matched control subjects (age range 29-47 years (mean \pm SD age, $38.8 \pm 7.6)$ ) were picked from among healthy patients with normal polysomnography (PSG) results attending the same clinic during this study period.

At study entry, medical history was recorded and a physical examination was performed to all participants.

\section{Anthropometry}

The anthropometric measures of all subjects were recorded (age, body-mass index (BMI), neck, waist and hip circumferences, waist-to-hip ratio (WHR)). Weight and height were measured to the kilogram and centimeter, respectively, and BMI was calculated (BMI $=$ weight $(\mathrm{kg}) /$ height $\left.^{2}\left(\mathrm{~m}^{2}\right)\right)$. Neck circumference was measured at the cricothyroid level, waist circumference in the middle between the 12th rib and the iliac crest, and hip circumference at the level of great trochanter by a tape, and WHR was calculated $(\mathrm{WHR}=$ waist circumference $(\mathrm{cm}) /$ hip circumference $(\mathrm{cm})$ ).

Correspondence to: Vural Fidan, MD, Department of Otorhinolaryngology, Yunus Emre Goverment Hospital, 26100 Eskisehir, Turkey, Tel: +90 50556068 42; E-mail: vuralf@mynet.com

Key words: obstructive sleep apnea syndrome, polisomnography, uvulopalatopharyngoplasty, vascular reactivity, vitamin-C

Received: June 07, 2017; Accepted: July 04, 2017; Published: July 07, 2017 


\section{Routine tests}

Routine blood and urine analyses, cardiopulmonary graphs, and chest radiographs were performed to all subjects. In blood samples, total cholesterol, low-density lipoprotein, very low-density lipoprotein and high-density lipoprotein cholesterol, and HbAlc values specially were assessed in all subjects. .

\section{Overnight polısomnography}

All subjects underwent an attended overnight polysomnography (PSG (Koninklijke Philips Electronics N.V./ Alice LE, Amsterdam, Netherlands)). PSGs were performed between 10:00pm - 06:00am. PSGs were assessed at baseline and repeated at the 8 weeks later than UPPP in the study group. PSGs were performed only one time (baseline) to the control subjects.

Apneas, hypopneas, and electroencephalography (EEG) recordings were automatically scored. Apnea was accepted as complete cessation of airflow more than $10 \mathrm{sec}$; hypopnea as a $50 \%$ reduction in airflow more than $10 \mathrm{sec}$, accompanied by more than $4 \%$ desaturation or by an EEG recorded arousal. Apnea-hypopnea index was calculated(AHI= total number of apneas and hypopneas /sleep time(hour)). In both groups, blood pressure values were taken from the right arm at the 4 hours intervals and averaged to compute the mean daytime blood pressure.

\section{Operation}

UPPP is a procedure designed to enlarge the potential airspace in the oropharynx. The uvula and part of the free edge of the soft palate were removed under general anesthesia.

\section{Endothelial function testing protocol}

The test was started at 15:00 in all cases. All subjects were scrutinized in the supine position after a resting period of $10 \mathrm{~min}$. Flow mediated dilatation (FMD) was measured by high-resolution ultrasonography (Acuson ; Siemens, Philadelphia/ USA) of the right brachial artery (BA). The vessel diameter was evaluated under resting baseline resting conditions. Later on, forearm blood ischemia was created for $5 \mathrm{~min}$ by inflating a cuff to suprasystolic pressures. The cuff was deflated, causing a dilation of the $\mathrm{BA}$, and arterial diameter was continuously monitored over a period of $3 \mathrm{~min}$. The rise in vessel diameter sighted 60 seconds after cuff liberation was determined and expressed in relative percent values as compared with baseline conditions. FMD in response to intravenous injection of vitamin C (totally $5 \mathrm{ml}$ ) (Vitabiol C; ; ascorbic acid $(500 \mathrm{mg} / 5 \mathrm{ml}))$ and sublingual application of nitroglycerine spray (totally $0.8 \mathrm{mg}$ )(Nitrolingual; glyceryl trinitrate $(0.4 \mathrm{mg} / \mathrm{puff})$ ) was measured.

\section{Exclusion criterias}

Study patients and control subjects with any clinical or laboratory evidence of vascular and metabolic diseases, those who had received vitamin therapy in the one month prior to the study, or those who were taking any drugs that might affect vascular reactivity (antihypertensive drugs, anticholesterol and endocrine agents), subject had a significant change in his body weight were also excluded from the study.

All subjects had given written informed consent to participate and the aim of the study and possible risks were fully explained. This study was acknowledged by the Ethical Committee of Eskisehir Osmangazi University Hospital.

\section{Statistics}

SPSS $^{\circ}$ software package, version 17.0 (SPSS Inc., Chicago, IL, USA) for Windows was used for the statistical analyses.
Continuous variables were presented as mean \pm SD and categorical variables were presented as percentage. Continuous variables, which were the characteristics of the groups were compared by one-way ANOVA. Categoric variables were anayzed using the chi-square test.

Within the study group, univariate analysis was performed to relate FMD to parameters of OSAS severity, such as AHI and other variables, such as BMI.

Data continuous variables were analyzed statistically using nonparametric tests, using the Friedman two-way ANOVA to establish the differences in arterial diameter occurring in response to reactive hyperemia and after vitamin $\mathrm{C} /$ nitroglycerine.

A value of $P<0.05$ was considered to be statistically significant.

\section{Results}

Thirty-nine (25 male, 14 female) patients were completed the study. Postoperative velopharyngeal insufficiency as a complication of UPPP occurred in one patient $(2.6 \%)$. He received u-shaped flap palatoplasty to cure the complication.

Anthropometric features of all subjects are shown in table 1. The two groups were matched in age, gender and anthropometric properties. There was no statistical difference between groups.

Sleep properties of all subjects are shown in table 2. Blood pressure were within the normal range and there was not statistical significant difference. AHI, oxygen desaturation index (ODI) results were higher in study group and they were decreased after UPPP.

As shown in table 3; there were no statistically difference in blood parameters between groups.

The preoperative baseline FMD was significantly lower in the study group when compared with the control group $(6.1 \pm 0.7 \%$; $8.9 \pm 1.1 \%(\mathrm{p}<0.001))$. After intravenous injection of $0.5 \mathrm{~g}$ vitamin

Table 1. Comparison of anthropometric characteristics between the two groups.

\begin{tabular}{|c|c|c|c|}
\hline & $\begin{array}{c}\text { Study Group } \\
(\mathbf{n = 3 9 )} \\
(\mathbf{m e a n} \pm \mathbf{S D})\end{array}$ & $\begin{array}{c}\text { Control Group } \\
(\mathbf{n = 2 7 )} \\
(\mathbf{m e a n} \pm \text { SD) }\end{array}$ & $\mathbf{p}$ \\
\hline Age (years) & $41.4 \pm 7.9$ & $38.8 \pm 7.6$ & 0.378 \\
\hline Sex (male/female) & $25 / 14$ & $16 / 11$ & 0.466 \\
\hline BMI (kg/m2) & $36.6 \pm 7.5$ & $34.7 \pm 6.3$ & 0.169 \\
\hline Neck circumference (cm) & $45.7 \pm 3.9$ & $44.8 \pm 3.5$ & 0.232 \\
\hline Waist circumference $(\mathrm{cm})$ & $123.1 \pm 15.3$ & $120.6 \pm 17.2$ & 0.187 \\
\hline Hip circumference $(\mathrm{cm})$ & $128.8 \pm 23.7$ & $125.3 \pm 25.7$ & 0.121 \\
\hline WHR & $0.96 \pm 0.07$ & $0.96 \pm 0.07$ & 0.909 \\
\hline
\end{tabular}

BMI: body mass index; WHR: waist to hip ratio.

Table 2. Characteristics of sleep properties between the conrol group and preoperativepostoperative result of study group.

\begin{tabular}{|c|c|c|c|c|}
\hline & \multicolumn{2}{|c|}{ Study Group $(n=39)$} & \multirow{2}{*}{$\begin{array}{c}\text { Control } \\
\text { Group }(n=27)\end{array}$} & \multirow{2}{*}{$\mathbf{p}$} \\
\hline & Preoperative & Postoperative & & \\
\hline Systolic BP (mmHg) & $133.9 \pm 7.8$ & $132.7 \pm 7.7$ & $132.2 \pm 7.4$ & 0.468 \\
\hline Diastolic BP (mmHg) & $82.7 \pm 7.3$ & $81.9 \pm 7.5$ & $80.9 \pm 7.6$ & 0.969 \\
\hline AHI (/hour) & $29.6 \pm 6.3$ & $18.9 \pm 5.8$ & $8.1 \pm 3.7$ & $<0.001$ \\
\hline FEV1 (\% pred.) & $90.1 \pm 8.9$ & $90.7 \pm 8.1$ & $92.2 \pm 7.8$ & 0.626 \\
\hline FVC (\% pred.) & $90.2 \pm 9.8$ & $89.9 \pm 9.5$ & $89.3 \pm 9.3$ & 0.528 \\
\hline $\mathrm{pH}$ & $7.42 \pm 0.02$ & $7.41 \pm 0.01$ & $7.41 \pm 0.01$ & 0.839 \\
\hline $\mathrm{PaO} 2(\mathrm{~mm} \mathrm{Hg})$ & $82.6 \pm 6.2$ & $82.9 \pm 6.2$ & $83.1 \pm 5.9$ & 0.126 \\
\hline $\mathrm{PaCO} 2(\mathrm{~mm} \mathrm{Hg})$ & $38.1 \pm 2.8$ & $38.2 \pm 2.5$ & $38.9 \pm 1.6$ & 0.814 \\
\hline ODI (times/hour) & $47.1 \pm 18.8$ & $19.3 \pm 5.3$ & $8.2 \pm 3.9$ & $<0.001$ \\
\hline
\end{tabular}

BP: blood pressure; AHI: apnea hypopnea index; FEV1: forced expiratory volume (1st second); FVC: forced vital capacity; ODI: oxygen desaturation index. 
Table 3. Crosscheck of blood parameters between the conrol group and preoperativepostoperative result of study group.

\begin{tabular}{|c|c|c|c|c|}
\hline & \multicolumn{2}{|c|}{ Study Group (n=39) } & Control Group & (n=27) \\
\cline { 2 - 4 } & Preoperative & Postoperative & p \\
\hline $\begin{array}{c}\text { Total cholesterol } \\
(\mathrm{mg} / \mathrm{dl})\end{array}$ & $103.4 \pm 14.3$ & $98.7 \pm 11.9$ & $94.1 \pm 10.2$ & 0.412 \\
\hline LDL (mg/dl) & $88.5 \pm 9.2$ & $79.6 \pm 8.8$ & $81.7 \pm 8.9$ & 0.571 \\
\hline HDL (mg/dl) & $47.3 \pm 6.1$ & $51.1 \pm 6.2$ & $50.2 \pm 5.7$ & 0.933 \\
\hline TG (mg/dl) & $107.7 \pm 11.9$ & $105.8 \pm 10.7$ & $98.4 \pm 9.1$ & 0.762 \\
\hline HbA1c (\%) & $5.4 \pm 0.1$ & $5.3 \pm 0.1$ & $4.9 \pm 0.1$ & 0.187 \\
\hline
\end{tabular}

HDL: high-density lipoprotein; LDL: low-density lipoprotein; TG: trigliserit; HbA1c: hemoglobinAlc.

Table 4. Flow-mediated dilation (FMD) of the brachial artery at baseline and after intravenous administration of vitamin $\mathrm{C}$ in the study (pre-post operative) and contro groups.

\begin{tabular}{|c|c|c|c|}
\hline & \multicolumn{2}{|c|}{ Study Group (n=39) } & \multirow{2}{*}{$\begin{array}{c}\text { Control Group } \\
(\mathbf{n = 2 7 )}\end{array}$} \\
\cline { 2 - 4 } & Preoperative & Postoperative & $8.9 \pm 1.1$ \\
\hline Baseline FMD (\%) & $6.1 \pm 0.7$ & $7.6 \pm 0.8$ & $8.8 \pm 1.1$ \\
\hline $\begin{array}{c}\text { FMD after intravenous } \\
\text { Vitamin C (\%) }\end{array}$ & $7.4 \pm 0.7$ & $7.7 \pm 0.9$ & \\
\hline
\end{tabular}

FMD: Flow mediated dilatation.

C, vasoreactivity remained unchanged in the control group $(8.9 \pm$ $1.1 \% ; 8.8 \pm 1.1 \%(\mathrm{p}=0.912))$. In the study group, vitamin $\mathrm{C}$ led to a statistically significant increase in preoperative FMD when compared with the preoperative baseline FMD $(6.1 \pm 0.7 \% ; 7.4 \pm 0.7 \%(\mathrm{p}<0.001))$. The preoperative baseline FMD was increased after UPPP (6.1 $\pm 0.7 \%$; $7.4 \pm 0.7 \%(\mathrm{p}<0.001))$. After UPPP in study group, vitamin $\mathrm{C}$ injection did not change the vasoreactivity $(7.6 \pm 0.8 \% ; 7.7 \pm 0.9 \%(\mathrm{p}=0.610)$. Also there was no difference between postoperative baseline FMD of study group and baseline FMD of control group $(7.6 \pm 0.8 \% ; 8.9 \pm 1.1 \%(\mathrm{p}=0.107))$.

\section{Discussion}

The present study demonstrates that endothelial dysfunction in patients with OSAS like as the literature $[15,16]$. And the endothelial dysfunction was reversed by intravenous injection of vitamin $\mathrm{C}$ in patients with OSAS. The possible factors that could effect the vasoreactivity were excluded in the subjects. We found that treating OSAS patients via UPPP can improve the endothelial function in OSAS patients without any changes in BMI. This is the sorter property of our study. In the published literature, there was shown that FMD in OSAS has been found to improve after several weeks of continuous positive airway pressure therapy $[15,17]$. But this is the first study about the changes of endothelial function before and UPPP in patients with OSAS comparing with healty controls.

Our study differs from the previous works in two ways. First, our groups were similar in all anthropometric characteristics, blood pressures, serum cholesterol and $\mathrm{HbAlc}$ levels which can effect the FMD $[15,18,19]$. But the published studies have many limitations such as, investigators applied the PSG only to patients, and their groups include any female subjects. Also they did not say anything about the anthropometric measurement of their subjects $[4,15,17]$.

Secondly, we assessed study group before and after UPPP operation. So this is the first published study which assesses the impact of UPPP on endothelial function in patients with OSAS.

The limitation of our study is that we did not investigate the longterm effects of UPPP on vascular reactivity in OSAS. The second limitation is that all subjects received the same dose of vitamin C. This study can not clarify the dose-response relationship between the amount of vitamin $\mathrm{C}$ and FMD in patients with OSAS.

\section{Conclusion}

Accumulating evidence suggest that OSAS has a role in the endothelial dysfunction associated with vascular disease and UPPP have comperable increase on FMD like antioxidant agent vitamin C. So, we need further investigation about the relation between the oxidative mechanisms, vascular reactivity and cardiovascular problems and the effect of UPPP on these issues in patients with OSAS.

\section{Conflicts of interest}

None declared.

\section{References}

1. Quan SF, Gersh BJ (2004) Cardiovascular consequences of sleep-disordered breathing: past, present and future: report of a work-shop from the national center on sleep disorders research and the national heart, lung, and blood institute. Circulation 109: 951-957. [Crossref]

2. Simonneau G, Galiè N, Rubin LJ, Langleben D, Seeger W, et al. (2004) Clinical classification of pulmonary hypertension. J Am Coll Cardiol 43: 5S-12S. [Crossref]

3. Peppard PE, Young T, Palta M, Skatrud J (2000) Prospective study of the association between sleep-disordered breathing and hypertension. N Engl J Med 342: 1378-1384. [Crossref]

4. Zamarrón C, Riveiro A, Gude F (2011) Circulating levels of vascular endothelial markers in obstructive sleep apnoea syndrome. Effects of nasal continuous positive airway pressure. Arch Med Sci 31: 1023-1028. [Crossref]

5. Dursunoaylu D, Dursunoaylu N (2011) Cardiovascular biomarkers in clinical practice of sleep apnea. Tuberk Toraks 59: 402-408. [Crossref]

6. Barceló A, Piérola J, de la Peña M, Esquinas C, Sanchez-de la Torre M, et al. (2012) Day-night variations in endothelial dysfunction markers and haemostatic factors in sleep apnea. Eur Respir J 39: 913-918. [Crossref]

7. Kent BD, Ryan S, McNicholas WT (2011) Obstructive sleep apnea and inflammation relationship to cardiovascular co-morbidity. Respir Physiol Neurobiol 178: 475-481. [Crossref]

8. Oztürk L, Mansour B, Yüksel M, Yalçin AS, Celikoğlu F, Gökhan N (2003) Lipid peroxidation and osmotic fragility of red blood cells in sleep-apnea patients. Clin Chim Acta 332: 83-88. [Crossref]

9. Lavie L (2003) Obstructive sleep apnoea syndrome - an oxidative stress disorder. Sleep Med Rev 7: 35-51. [Crossref]

10. Goodman M, Bostick RM, Kucuk O, Jones DP (2011) Clinical trials of antioxidants as cancer prevention agents: past, present, and future. Free Radic Biol Med 51: 1068 1084. [Crossref]

11. Traber MG, Stevens JF (2011) Vitamins C and E: beneficial effects from a mechanistic perspective. Free Radic Biol Med 51: 1000-1013. [Crossref]

12. Gori T, Münzel T (2011) Oxidative stress and endothelial dysfunction: therapeutic implications. Ann Med 43: 259-272. [Crossref]

13. Park JG, Ramar K, Olson EJ (2011) Updates on definition, consequences, and management of obstructive sleep apnea. Mayo Clin Proc 86: 549-554. [Crossref]

14. Simunjak B, Slipac J, Krmpotić P, Dubravcić-Simunjak S (2011) Efficiency of radiofrequency assisted uvulopalatopharyngoplasty in the treatment of snoring. Acta Clin Croat 50: 357-360. [Crossref]

15. Grebe M, Eisele HJ, Weissmann N, Schaefer C, Tillmanns H, et al. (2006) Antioxidant vitamin C improves endothelial function in obstructive sleep apnea. Am J Respir Crit Care Med 173: 897-901. [Crossref]

16. Oyama J, Yamamoto H, Maeda T, Ito A, Node K, Makino N (2012) Continuous positive airway pressure therapy improves vascular dysfunction and decreases oxidative stress in patients with the metabolic syndrome and obstructive sleep apnea syndrome. Clin Cardiol 35: 231-236. [Crossref]

17. Duchna HW, Guilleminault C, Stoohs RA, Faul JL, Moreno H, et al. (2000) Vascular reactivity in obstructive sleep apnea syndrome. Am J Respir Crit Care Med 161: 187-191. [Crossref]

18. Shankar SS, Steinberg HO (2005) Obesity and endothelial dysfunction. Semin Vasc Med 5: 56-64. [Crossref]

19. Nieto FJ, Herrington DM, Redline S, Benjamin EJ, Robbins JA (2004) Sleep apnea and markers of vascular endothelial function in a large community sample of older adults. Am J Respir Crit Care Med 169: 354-360. [Crossref]

Copyright: (C2017 Fidan V. This is an open-access article distributed under the terms of the Creative Commons Attribution License, which permits unrestricted use, distribution, and reproduction in any medium, provided the original author and source are credited. 